\title{
Satellite-Based Crop Monitoring and Yield Estimation-A Review
}

\author{
Olipa N. Lungu ${ }^{1}$, Lydia M. Chabala ${ }^{1} \&$ Chizumba Shepande ${ }^{1}$ \\ ${ }^{1}$ School of Agricultural Sciences, University of Zambia, Lusaka, Zambia \\ Correspondence: Olipa N. Lungu, School of Agricultural Sciences, University of Zambia, Lusaka, Zambia. Tel: \\ 260-211-295-421. E-mail: olipa.kamanga@unza.zm
}

Received: August 1, 2020

doi:10.5539/jas.v13n1p180
Accepted: December 1, $2020 \quad$ Online Published: December 15, 2020

URL: https://doi.org/10.5539/jas.v13n1p180

\begin{abstract}
To sustain food security and crop condition monitoring, yield estimation must improve at local and global scales. The aim of this review was to give a background of satellite-based crop monitoring and crop yield estimation, including the use of crop models. Recently, most advances in remote sensing techniques, aimed at complimenting the traditional crop harvest surveys, have focused on high-production and information-rich areas. However, there is limited research in dynamic landscapes using these techniques at local scales in most Southern African countries. Models such as the Decision Support System Agro-Technology's (DSSAT) CERES-model, and Agricultural Production Simulator (APSIM) have been used to simulate maize biophysical parameters and yield variability in a changing climate. Despite the successes, there is still need to consider yield prediction using simplified models that decision-makers can use to plan for food support and sales. The application of freely-available satellite data with focus on maize crop as a staple for Southern Africa, highlights some challenges such as heavy reliance on agro-meteorological estimations and regional estimations of crop yield. It also raises questions of predicting across large growing belts without consideration of diverse cropping patterns. Conversely, future opportunities in crop monitoring and yield estimation using remotely sensed-data still shed a light of hope. For instance, employing multi-model configurations or multi-model ensembles is one of the major missing gaps needing consideration by crop modeling research. Other simpler, but versatile opportunities are the use of crop -monitoring applications on smart phones by small holder farmers to provide phenological data to decision makers throughout a growing season.
\end{abstract}

Keywords: crop condition monitoring; crop yield estimation; food security; remote sensing; vegetation indices

\section{Introduction}

Crop condition monitoring and yield estimations must continuously produce timely, and spatially dependable updates for decision support systems. However, exorbitant survey costs, and complexity of production systems often impede these. Meanwhile, millions are affected by severe food insecurity in the advent of projected extreme climatic events (Godfray et al., 2010; Hall et al., 2017; Allen et al., 2014; Wheeler \& Von Braun, 2013; Knox et al., 2012; Leff et al., 2004). In this respect, crops such as rice, maize, and wheat, which constitute the world's major sources of energy, now demand increased special attention (UN SDGs, 2015). Correspondingly, global, regional and local scale monitoring of condition and production of these crops is essential to ensure food security. This, in turn, has great potential of achieving and sustaining the sustainable development goal (SDG) number two of "Zero Hunger" (UN SDGs, 2015).

Generally, agriculture accounts for the main source of livelihood, and is a key sector in economic development, especially in most developing nations. It is dominantly characterized by cultivation of maize, rice, soybeans, wheat, tubers and cotton. As the population in sub-Saharan Africa is projected to double by 2050, the status quo necessitates vigilance in managing water and land resources to meet heightening food production demands (Van Ittersum, 2016). Currently, water scarcity recorded in parts of Eastern and Southern Africa, following recurring droughts, due to El-Niño events, confirmed the need for effective resource management (Msowoya et al., 2016). Erratic rainfall prevailing in most production areas is increasing the hunger situation, especially in remote areas. These profound climatic impacts have a bearing on crop demand and supply, thereby requiring subtle monitoring and prediction systems. As unfavorable climatic events continue hampering agriculture, consistent crop monitoring and yield estimation will form an imperative basis of management and increased global resilience. With this information, relevant stakeholders can make timely and more accurate decisions during disasters and surplus production. These efforts are indispensable if the world is to overcome the eminent challenge of feeding 
billions of people. According to Godfray et al. (2010), there will be more than 9 billion people across the world by mid-century, and as such food production to meet their demands will require augmented efforts than ever before.

Satellite-based remote sensing offers a unique and robust opportunity for crop monitoring and yield estimation, which is more essential in data-scarce areas at dynamic scales (Srivastava et al., 2017). Since data collection in large production areas is very costly, tedious, and time-consuming, the combined use of satellite imagery and ground data collection to monitor crop condition, and subsequently predict yields, is not only convenient but also economical. Fortunately, innovations of state-of-the-art satellite missions have taken an impressive turn over the decades resulting in remarkable contributions to precision agriculture (Biffis \& Chavez, 2017) and cross-cutting sectors such as ecosystem services, health, soil mapping and socio-economic development (Bellora et al., 2017; Erickson, 1984; Shepande, 2010; Ferencz et al., 2004). The results of these undertakings, such as soil mapping and delineation of agroecological regions, are useful in decision-making and policy directions on resource management (Chapoto et al., 2016; Burke \& Lobell, 2017).

Steady provision of satellite imagery has seen an exponential rise in usage though there is a continuous trade-off between high spatial and low temporal resolution data (Unganai \& Kogan, 1998; Battude et al., 2016; Dong et al., 2016; Wu et al., 2015, 2017; Senay et al., 2015). Often times, there is usually no getting the best of both worlds as some high spatial resolution data has low temporal resolution and vice versa. Therefore, the onus of which imagery to use is on the purpose of the study and availability of data for a given area of interest. For instance, continued free accessibility of Landsat images over the decade has notably been a major driver of success in monitoring crop conditions. Similarly, global coverage and availability of high resolution data continue to influence the rate of its use in most studies, and satellite data present uniquque challenges and opportunities for the future. This review aims at enlighting the information on use of satellite derived biophysical parameters in crop monitoring and crop yield estimations with relations to crop models, with particular interest in Southern Africa, where food insecurity is worsening in a changing climate.

\section{Crop Monitoring and Crop Yield Estimation}

The major staple crop in Southern Africa is maize, and is the main crop under this review. This work however, also takes a glance at global successes in crop monitoring and crop yield estimation using satellite remote sensing techniques, and then dives into specifics in Southern Africa. It stems from several online sources in form of reports, reviews, communications, books, and research articles. Search engines were used to find this information and the approach taken are summarized in Figure 1. The most prominent sources included, but not limited to Elsevier, Google Scholar, Web of Knowledge, and Google Search using key words crop yield, crop model, crop monitoring, maize, remote sensing, satellite, Southern Africa, vegetation indices, and Zambia.

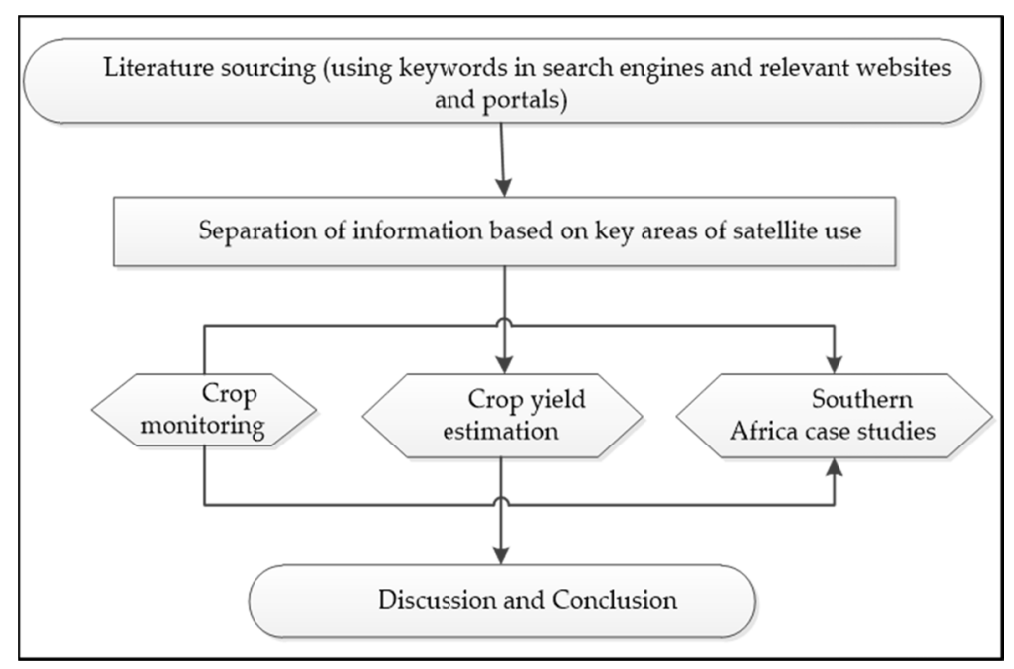

Figure 1. Flowchart of crop yield estimation based on satellite remote sensing approaches

Source: From the author. 


\subsection{Crop Monitoring}

Globally, the Land and Crop Inventory Experiment (LACIE) emerged as a successful pioneering effort in crop condition monitoring (Erickson, 1984). With this foundation, several other attempts followed, leading to more timely and improved crop condition and yield forecasting (Ferencz et al., 2004; Unganai \& Kogan, 1998; Battude et al., 2016; Dong et al., 2016). Currently, improved recent developments such as the Monitoring Agricultural Resources (MARS) and CropWatch (Wu et al., 2015, 2017) continue to offer a huge contribution to global and regional crop monitoring. The emphasis of monitoring is on European production for MARS, while CropWatch has a more global coverage of more than 173 countries. Early warning systems such as the Global Information Early Warning System (GIEWS) and Famine Early Warning System Network (FEWS NET), similarly monitor short-term crop conditions using remote sensing and climatic data (Senay et al., 2017; Ross et al., 2009). Like in other parts of the world, food security is a very topical issue in Africa. To address this issue, FEWS NET (which employs satellite images) is currently one of the main crop forecasters per country on the continent, and it provides a candid basis for decision-making. The guiding principle behind satellite imagery use generally relates to the unique spectral signatures of things in the electromagnetic spectrum. The specific reflectance of soil, water and vegetation, etc. allows information to be inferred and interpreted for crop mapping, monitoring, yield estimation, water resources management, as illustrated in Figure 2. Crop condition mapping and yield predictions, utilize information from the spectral response of specific crops.

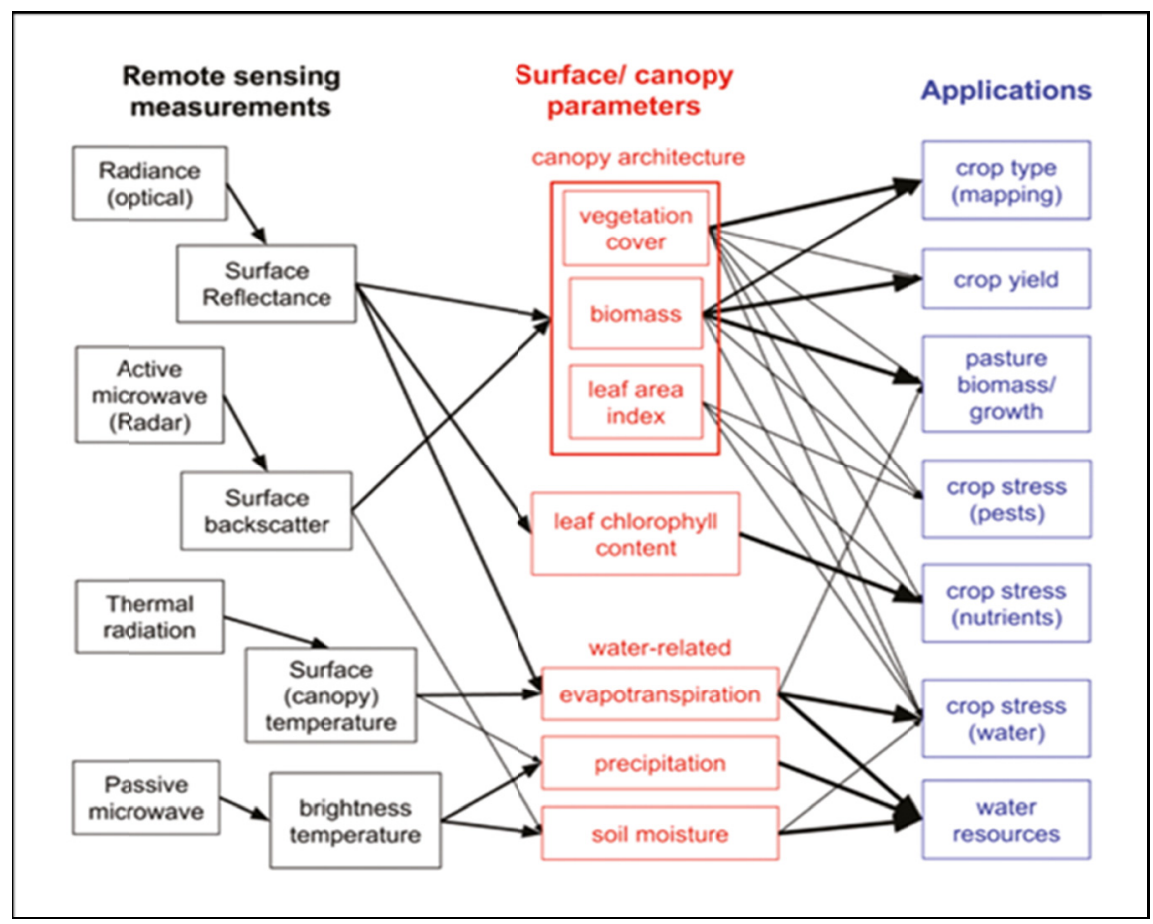

Figure 2. Scheme showing remote sensing applications in agriculture

Source: Guerschman et al. (2016).

\subsubsection{Satellite-Derived Biophysical Parameters}

Moderate-resolution Imaging Spectrometer (MODIS) products are one of the freely available datasets that provide considerable advantage in crop monitoring studies (Ban et al., 2015; Ma et al., 2013; Zhang et al., 2015; Kim et al., 2012; Liaqat et al., 2017). However, exact methods of crop condition and yield estimation vary from study to study, and many indices have been proposed thus far (Table 1). Currently, there exists no consensus on the best method to employ for each region, though some indices like the normalized difference vegetation index (NDVI) frequently indicate crop condition. Leaf area index (LAI) is another useful biophysical parameter in estimating yield. It is denoted as the area of one side of the green leaf as a ratio of the unit ground area covered by the plant. 
Table 1. Commonly used vegetation indices (VIs) in crop monitoring. Modified from Atzberger (2013)

\begin{tabular}{lll}
\hline Index & Formula & Reference \\
\hline Normalized Difference Vegetation index NDVI & $(N I R-$ Red $) /(N I R+R e d)$ & Rouse et al. (1974) \\
Soil Adjusted Vegetation Index (SAVI) & $(1+0.5) \times(N I R-R e d) /(N I R+R e d+0.5)$ & Huete $(1988)$ \\
Simple Ratio (SR) & NIR/Red & Jordan $(1969)$ \\
Renormalized Difference Vegetation Index (RDVI) & $(N I R-$ Red $) /[\operatorname{sqrt}(N I R+R e d)]$ & Roujean (1995) \\
Enhanced Vegetation Index. (EVI) & {$[2.5 \times(N I R-R e d)] /(1+N I R+6 \times$ Red $-7.5 \times$ Blue $)$} & Huete et al. (2002) \\
\hline
\end{tabular}

Several other indices have been developed for monitoring vegetation and crop chlorophyll content and are presented in Table 2. These indices vary from each other depending on the spectral bands they use to monitor the crop phenology.

Table 2. Vegetation indices summary

\begin{tabular}{|c|c|c|c|}
\hline Name & Type & Abbrev. & Equation \\
\hline Ratio vegetation index (also called simple ratio) & Red-NIR & RVI & $R_{n} / R_{r}$ \\
\hline Normalized difference vegetation index & Red-NIR & NDVI & $\left(R_{n}-R_{r}\right) /\left(R_{n}+R_{r}\right)$ \\
\hline Soil adjusted vegetation index & Red-NIR & SAVI & $(1+0.5)\left(R_{n}-R_{r}\right) /\left(R_{n}+R_{r}+0.5\right)$ \\
\hline Modified soil adjusted vegetation index & Red-NIR & MSAVI & $0.5\left\{2 R_{n}+1-\sqrt{\left[\left(2 R_{n}+1\right)^{2}-8\left(R_{n}-R_{r}\right)\right]}\right\}$ \\
\hline Optimized soil adjusted vegetation index & Red-NIR & OSAVI & $(1+0.16)\left(R_{n}-R_{r}\right) /\left(R_{n}+R_{r}+0.16\right)$ \\
\hline Enhanced vegetation index & Vis-NIR & EVI & $2.5\left(R_{n}-R_{r}\right) /\left(R_{n}+6 R_{r}-7.5 R_{b}+1\right)$ \\
\hline Triangular vegetation index & Vis-NIR & TVI & $0.5\left[120\left(R_{n}-R_{g}\right)-200\left(R_{r}-R_{g}\right)\right]$ \\
\hline Second modified triangular vegetation index & Vis-NIR & MTVI2 & $1.5\left[2.5\left(R_{n}-R_{g}\right)-2.5\left(R_{r}-R_{g}\right)\right] / \sqrt{\left[\left(2 R_{n}+1\right)^{2}-6 R_{n}-5 \sqrt{\left(R_{r}\right)}-0.5\right]}$ \\
\hline Chlorophyll vegetation index & Vis-NIR & CVI & $R_{n} \cdot R_{r} / R_{g}^{2}$ \\
\hline Green normalized difference vegetation index & Green-NIR & gNDVI & $\left(R_{n}-R_{g}\right) /\left(R_{n}+R_{g}\right)$ \\
\hline Chlorophyll index-green & Green-NIR & CI-G & $R_{n} / R_{g}-1$ \\
\hline Normalized green red difference index & Vis & NGRDI & $\left(R_{g}-R_{r}\right) /\left(R_{g}+R_{r}\right)$ \\
\hline Green leaf index & Vis & GLI & $\left(2 R_{g}-R_{r}-R_{b}\right) /\left(2 R_{g}+R_{r}+R_{b}\right)$ \\
\hline Visible atmospherically resistant index & Vis & VARI & $\left(R_{g}-R_{r}\right) /\left(R_{g}+R_{r}-R_{b}\right)$ \\
\hline Normalized difference red edge index & RE-NIR & NDREI & $\left(R_{n}-R_{r e}\right) /\left(R_{n}+R_{r e}\right)$ \\
\hline Chlorophyll index-red edge & RE-NIR & CI-RE & $R_{n} / R_{r e}-1$ \\
\hline MERIS total chlorophyll index & RE-NIR & MTCI & $\left(R_{750}-R_{710}\right) /\left(R_{710}-R_{680}\right)$ \\
\hline Modified chlorophyll absorption reflectance index & Red-RE & MCARI & {$\left[\left(R_{700}-R_{670}\right)-0.2\left(R_{700}-R_{550}\right)\right]\left(R_{700} / R_{670}\right)$} \\
\hline Transformed chlorophyll absorption reflectance index & Red-RE & TCARI & $3\left[\left(R_{700}-R_{670}\right)-0.2\left(R_{700}-R_{550}\right)\right]\left(R_{700} / R_{670}\right)$ \\
\hline Triangular chlorophyll index & Red-RE & TCI & $1.2\left(R_{700}-R_{550}\right)-1.5\left(R_{670}-R_{550}\right) \sqrt{\left(R_{700} / R_{670}\right)}$ \\
\hline Combined index with TCARI & Red-RE-NIR & & TCARI/OSAVI \\
\hline Combined index with MCARI & Vis-RE-NIR & & MCARI/MTVI2 \\
\hline Triangular greenness index & Vis & TGI & $-0.5\left[\left(\lambda_{r}-\lambda_{b}\right)\left(R_{r}-R_{g}\right)-\left(\lambda_{r}-\lambda_{g}\right)\left(R_{r}-R_{b}\right)\right]$ \\
\hline
\end{tabular}

Source: Hunt et al. (2013).

In a separate review on methods of estimating biomass and yield using low-resolution satellite data, Rembold et al. (2013) highlighted three main aspects, being that;

Several indices to estimate leaf chlorophyll content exist (Hunt et al., 2013). The trade-off on which index to employ is also driven by the type of imagery available for a given study area and period. For instance, Sentinel 2 has the red edge bands which Landsat 8 does not, yet Landsat 8 is likely to cover more of a particular area.

Crop residues after senescence can quantify biomass using the characteristic lignin and cellulose reflectance at 2.0-2.2 $\mu \mathrm{m}$.

Vegetation index derived LAI and fPAR are important in biomass and yield estimations. NDVI, SAVI, EVI from MODIS, SPOT-Vegetation and PROBA-V data using artificial neural networks and other computational techniques are among the frequently used biophysical parameters for yield estimation studies. 
Crop canopies provide vital indicators in crop biomass accumulation and stress responses based on their spectral reflectance usually in the red and infrared bands. This is because healthy plants absorb the blue and red, and reflect the green of the optical spectrum, while they reflect infrared radiation. Therefore, NDVI reflects the photosynthetic activity of crops and shows the biomass conditions and stress of photosynthetically active crops (Liu, 2010). For estimating crop yields, Atzberger (2013) recommended that crop-specific masks be employed to eliminate analysis of other crops within observation area. Generally, this entails developing updated country or county crop masks of specific crops. With the advancement in technology and availability of satellite data, this should not be a hurdle in most cases. On the other hand, rigorous crop classification to identify the crops before analysis is an essential pre-requisite together with the crop masks.

\subsection{Crop Yield Estimations}

Satellite-based crop yield predictions employ similar approaches centered on spectral signatures and the estimated yields can be as reliable as actual yields. However, unprecedented (over or under-estimated) results obtained exist, and these can sometimes be alluded to edaphic and climatic conditions prevailing after the prediction. Particularly, paucity of data on actual yields in some areas can amplify the discrepancy between estimated and actual yields. Nonetheless, studies have shown success in maize yield predictions under varying environments (Zhang et al., 2016; Vergara-Díaz et al., 2016; Ban et al., 2016).

\subsubsection{Machine Learning and Big Data in Crop Yield Estimations}

Machine learning processes that capture information about a crop and deduce yields using various algorithms have proved to be a useful tool in predicting yields. However, these technologies need more scaling up on the continents if they are to provide meaningful contribution to crop yield estimations. You et al. (2017) using MODIS satellite data, applied deep learning techniques to train the data, and applied a Gaussian algorithm to obtain more smoothed results. Yield for the counties studied were accurately estimated thereafter. Machine learning's ability to handle simple and complex relations between variables presents itself as a powerful tool for processing big data (Biffis \& Chavez, 2017). In related instances, other studies have employed satellite data with convolutional, and or artificial neural networks to monitor crop condition and estimate yields (Fieuzal et al., 2017; Ali et al., 2017; Saeed et al., 2017).

Scaling up such studies to regional areas can increase challenges of processing and storage of remote sensing data. Hats off to Google for the creation of Google earth engine (GEE), that allows performance of tasks involving several terabytes of data in a cloud platform. Google earth engine is a robust planetary-based platform, which successfully allows researchers and other stakeholders to perform numerous tasks without worrying about story space and preprocessing time. Gorelick et al. (2017) powerfully demonstrate the usefulness of GEE as a planetary-based platform for analyzing satellite imagery for several purposes including mapping vegetation conditions. Similarly, using GEE, Jain et al. (2017) proposed a newly developed scalable crop yield mapper. Interesting findings about corn yield variability were revealed in the corn belt of the USA through this platform. However, like all new algorithms, there is still room for improvement, especially in areas such as space provided per given user, user inability to influence a query once it is processing in the background, and the scaling challenge, which limits the configuration of huge machines using the platform.

\subsubsection{Satellite-Derived Data Assimilation in Crop Models}

Crop growth models are known to differ from applicability, development, purpose and robustness, though they generally fall under three main types; Remote sensing forecast, Crop simulation and Statistical models, which are built on the utilization of information from remote sensing forecasts and simulation models. Water is the main sub-model driving the differences in yield in these models. Short-comings arising from the use of most of these models are their limitation to be scaled up at regional level as most have been developed and work well under field conditions. To address this, and ensure models offer sustainable technological transfer, models such as DayCent, GLAM, and PEGASUS have been developed to cater for large domains. However, these models are still not very widely adopted for further research and offering decision-makers support. DSSAT models are distinguished for being reasonably robust and easy to integrate diverse domains.

As land use and climate change continue to affect the socio-economic status of people, it is timely to increase the incorporation of these factors in the crop models. Furthermore, synergistic efforts are needed amongst developers in order to create more dynamic, robust and acceptable models. The BioMA framework of the European Union offers an interesting platform for decision-makers, and scientists to alter model components, and even develop their own models to best suit their prevailing conditions. At a time when many models become obsolete because of lack of flexibility of changes, BioMA delivers a splendid way to deter such occurrences. 
Jones et al. (2016) quite explicitly revealed that crop models offer a comparative advantage in estimating crop yields and have various input requirements depending on their designs and purpose. According to Delincé's (Delincé, 2017) recent review of models in use for crop yield estimation, crop models vary in spatial and temporal terms, as well as scientific use and are classified as such WOFOST, APSIM, CROPSYST, DSSAT, STICS, EPIC, and ORYZA are among the widely used models in crop studies (Table A1) (Delincé, 2017).

The possibility of using remote sensing data in place of ground data makes most models more applicable for use in data-scarce areas. For instance, Leaf Area Index (LAI) derived from satellite data has been assimilated in studies as a forcing, or steering factor (Ma et al., 2013; Sun et al., 2017; Silvestro et al., 2017) (When assimilated as a forcing factor, the derived parameter is used directly in the model. When steering on the other hand, a model is re-parameterized and calibrated to reduce the difference between the model value and the satellite-derived value).

Similarly, Li et al. (2017) using CERES Wheat model and GF-1 data estimated wheat yield at county scale. After assimilating satellite-derived LAI using the particle filter method, more reliable yields were obtained compared to the unassimilated estimates. Largely, this may always hold true depending on the accuracy of the derived LAI. This is so because usually, cloud cover influences dependability of the optical satellite-derived data. In a related study, in comparing results obtained from GF-1, Landsat 8, and Huanjing (HJ-1), Li et al. (2015) discovered a strong correlation between the LAI and the Vis.

In a related study, Ban et al. (2016) while investigating corn in the USA, successfully predicted yield using a phenology model and MODIS-derived LAI (Ban et al., 2016). However, in this method, problems of mixed-pixel could arise, especially when very small areas were under consideration. Another setback is the temporal resolution of data and poor satellite coverage. Disruptions in the data availability of the satellite information concerning the cropping period impose a marginal impact on the precision of yield estimation.

While crop yield estimation methods are not a 'one-size-fits-all', the underlying principles of vegetation response to environmental and climatic conditions continue to drive all of them. Interestingly, Kuri et al. (2017) reported that the estimation of crop yield should take an in-depth account of phenology per given area. Crop phenology, can be related to decadal differences in weather parameters, using regression expressions (Figure 3). Based on this, estimated yield can be well correlated to the prevailing conditions at the time of estimation (Kuri et al., 2017). This has an advantage of highlighting some of the drivers to yield differences.
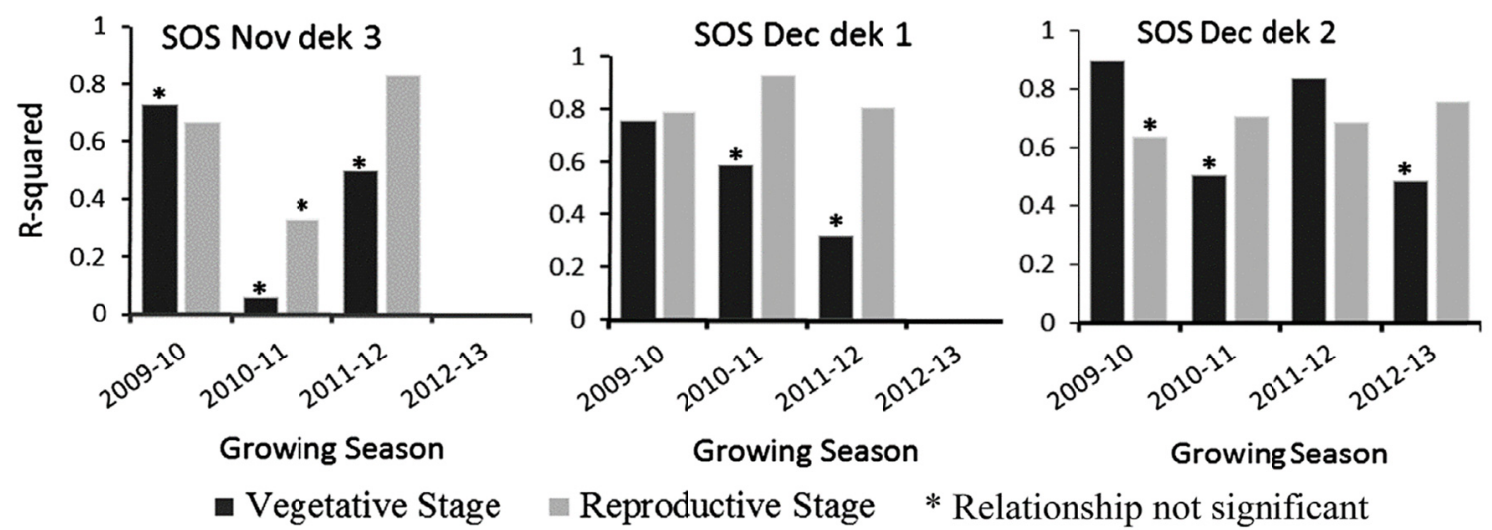

Figure 3. Regression model comparison between number of dry dekads and yield at two critical stages based on start of the season (SOS) in Zimbabwe

Source: Kuri et al. (2017).

Vegetation condition indices obtained using this method showed that reliable yield estimates can be obtained. This is understood that actual yields recorded also need to be reliable as was the case in this study (Unganai \& Kogan, 1998). Before disputing or disregarding yield estimation, it is therefore, relevant for stakeholders to seek to understand the estimation period. Steele-Dunne et al.'s (2017) synthesis of radar satellite use in agriculture delivers a diverse range of scenarios in crop monitoring and arising challenges and opportunities Wójtowicz et al. (2016) in a review of remote sensing applications in agriculture present various indices and the applications for which they were developed, enriching the already known and commonly used indices (Delincé, 2017). 


\subsubsection{Exploration of Sentinel 2 and Gaofen 1 Satellite Data in Crop Monitoring and Yield Estimation}

Among some recently launched state-of-the-art satellites are the Chinese Gaofen and the European Sentinel. Studies using free datasets from these missions, though few, equally unveil exciting potential in crop condition monitoring and crop yield estimations. The robustness of Sentinel 2 is embedded in its high spatial and temporal resolution, $10 \mathrm{~m}, 20 \mathrm{~m}, 60 \mathrm{~m}$ and 12 days respectively. Similarly, Gaofen-1 (GF-1) boasts of $2 \mathrm{~m}, 8 \mathrm{~m}$ and $16 \mathrm{~m}$ spatial resolution with a 10-day revisit period. Both Sentinel and Gaofen-1 are thrills in the developments of satellite missions bent at improving resource management. The GF-1, like Sentinel-2 has optical, infrared, thermal, and microwave sensors. Wei et al. (2017) reported successful application of G1-1 data in crop yield estimation. In another study, Zheng et al. (2016), in estimating wheat yield of two sites (Figure 4), also used high-resolution GF-1 data, which gave fairly good results.
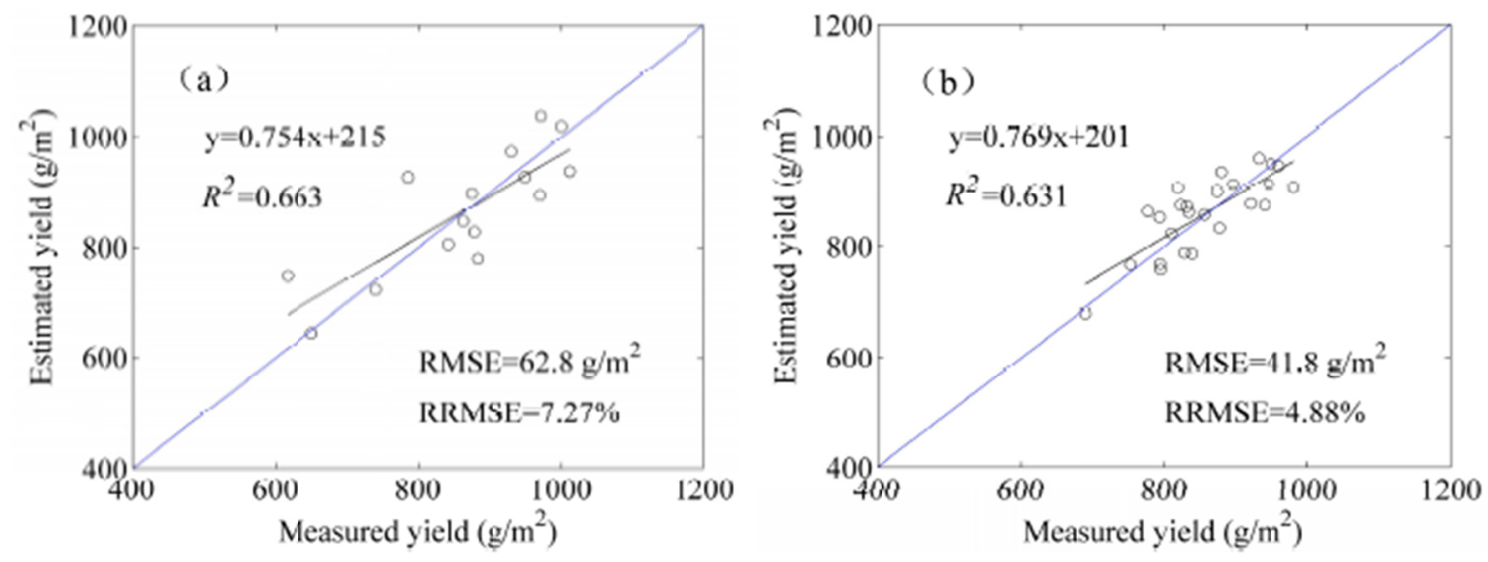

Figure 4. Measured and estimated yield for two sites (a) and (b)

Source: Zheng et al. (2016).

Having determined the above ground biomass relationship with the harvest index, yield was successfully obtained. Furthermore, results showed that site (a) recorded a slightly better estimation of wheat yield, even though their $\mathrm{R}^{2}$ at $95 \%$ confidence level was not so different from each other.

In a similar study, Clevers (2017) while using Sentinel-2 $10 \mathrm{~m}$ spatial resolution data, established developmental parameters of a potato (Figure 5). This resolution was effective in isolating the LAI, leaf canopy content (LCC) and leaf chlorophyll content (CCC). The weighted difference vegetation index (WDVI), in this study illustrated a reliable relationship with LAI.
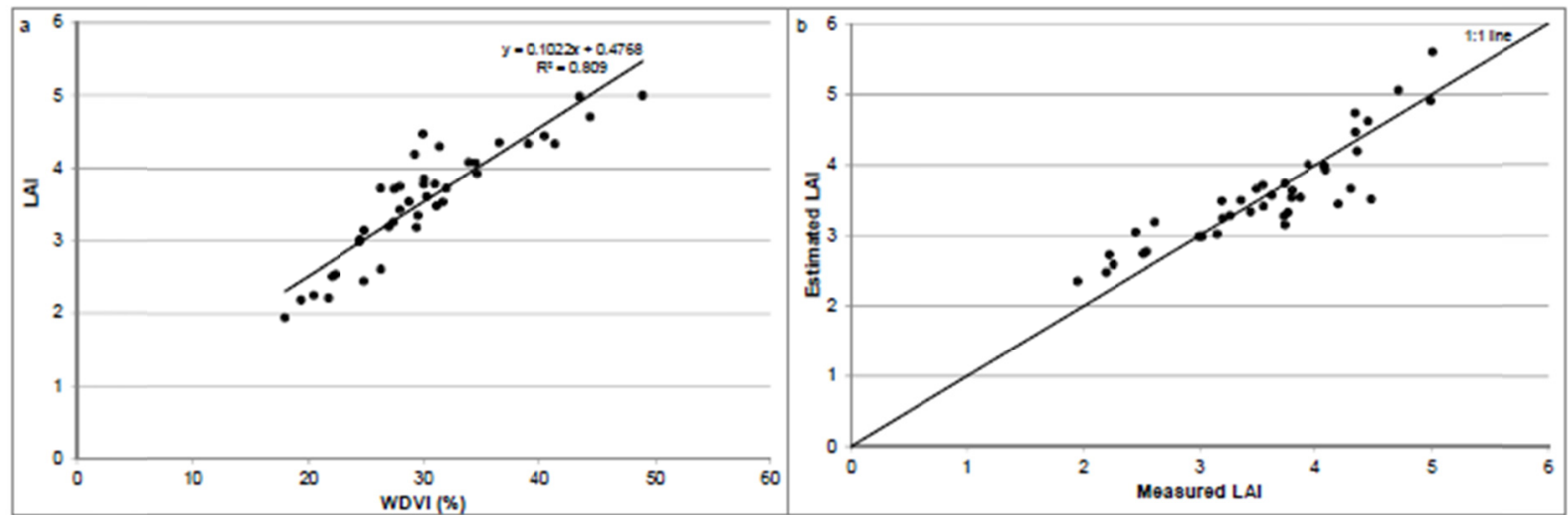

Figure 5. Relationships between (a) LAI and WDVI and estimated and (b) measured LAI for the potato plant Source: Immitzer et al. (2016). 
However, in using Sentinel data, as for the bands 1, 9 and 11, studies indicated that there were unreliable for monitoring vegetation condition. The short-wave-infra-red (SWIR), on the other hand, is a notably interesting band to indicate water stress (Immitzer et al., 2016).

While Sentinel 2-A has demonstrated its usefulness in crop condition monitoring, blending it with synthetic aperture radar (SAR) Sentinel 1-A revealed a much higher resolution LAI (Jain et al., 2017). This approach poises Sentinel data as one of the existing dependable datasets to contribute to agronomic research, among other uses.

The commonality in these approaches is that they do not have any standard procedure of determination, yet yield meaningful results. This unique aspect presents satellite-based yield estimation as a dynamic and important endeavor.

\subsection{Southern Africa Case studies}

While evidence suggests several crop monitoring and yield estimation studies in developed countries, only a few have been fully documented. Presented herein are successes in sub-Saharan Africa with particular attention to Southern Africa, where data scarcity in these areas exacerbates the digitization of the much needed production information. The prominent feature of most crop production in the region is the tiny cultivated area (Ntukamazina et al., 2017). Mapping crop types and yield in these areas has been very challenging. In the recent past, increased satellite data available has allowed this hurdle to be overcome. For instance, Burke and Lobell (Burke \& Lobell, 2017), working with smallholders in Kenya provided a typical set-up of most subsistence farmers in sub Saharan Africa. Citing droughts as one of the major disasters affecting maize yield in the region, Kuri et al. (2017) revealed interesting findings of maize yield predictions based on dry dekads, which revealed that dry dekads at vegetative stage could be more useful in early warning systems. While temperature and rainfall are important variables affecting crop growth conditions and yield, nutrient variability and deficiency can cause severe crop damage and yield losses in farming systems. Shoko and Mutanga (2016) indicated problems of multi-collinearity springing from hyperspectral data in prediction of nutrient variability in $\mathrm{C} 3$ and $\mathrm{C} 4$ plants. The high-resolution satellite data can also effectively map this variability (Figure 6). Maize is an important C4 plant that is predominantly cultivated in southern Africa and where necessary, it can benefit from this knowledge.
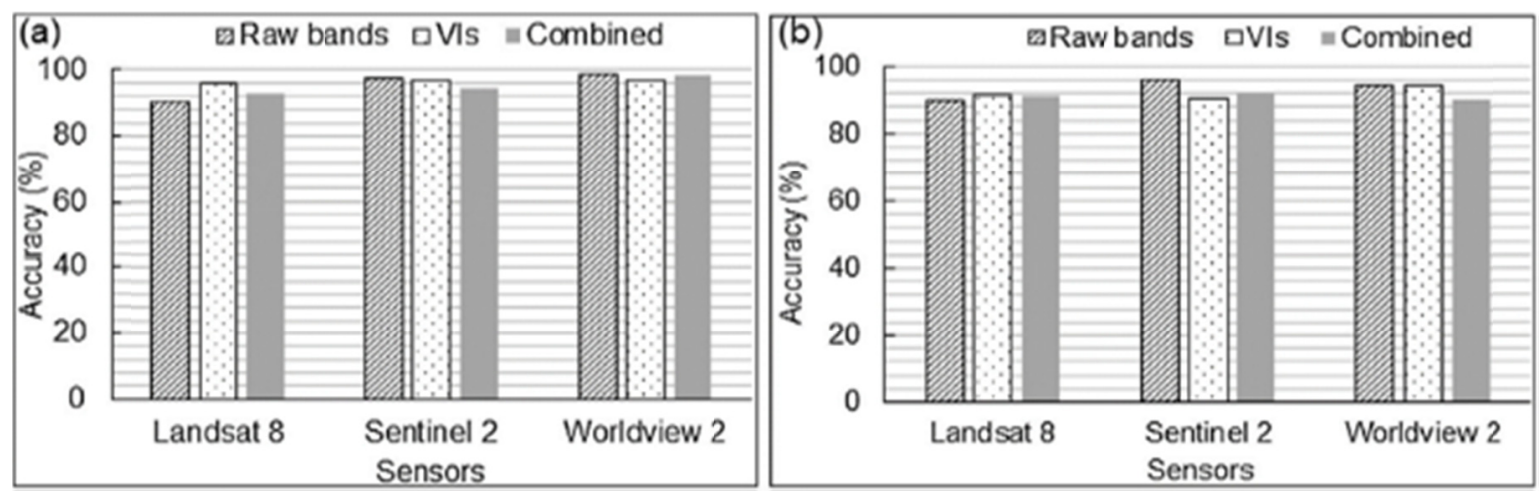

Figure 6. Overall accuracies obtained from resampled variables of Landsat 8, Sentinel 2 and Worldviewsensors for (a) summer and (b) winter

Source: Shoko and Mutanga (2016).

Van Oort et al. (2015) using ORYZA2000 in yield gap analysis to test heat induced sterility in rice in Zambia and seven other arid region countries established that it is well adapted to make estimations in arid regions. Spatial and temporal yield gaps are common and increasingly high in the tropics and the lowest production areas. The Global Yield Gap Atlas which covers about 43 countries including maize, rice and wheat producers, is a reliable model in the region. While this model depicts the sensitivity of rice to climatic factors, its operational requirements of at least 15-20 years' precipitation data can be limiting in remote areas. Similarly, Chisanga et al. (2015) showed that CERES maize models successfully predict maize yield under different climatic scenarios, increasing understanding of variability under different forcing. 


\section{Challenges and Opportunities in Crop Monitoring}

\subsection{Satellite Data, Yield Factors and Crop Monitoring Indices}

In vegetation studies, addressing challenges of pixel-based separation, crop identification, weed detection at early stage and cloud contamination differs according to nature of study, satellite data used and percent of accuracy required. For instance, Ma et al. (2013) reported the mixed-pixel effect while assimilating satellite-derived LAI into a crop model. This can complicate and reduce the accuracy of results especially in small study areas with heterogeneous vegetation. Using Fourier functions, the recalibration of the world food studies (WOFOST) model was performed which resulted in improved prediction results. Mostly, algorithms and digital filters such as the Savitzky-Golay (SG) have equally played incredible roles in smoothing data and reducing noise, common to satellite data. In the case of missing or cloud contaminated data, fusion of satellite data has proved to overcome this challenge. For instance, resampled high-resolution data to a much coarser resolution successfully estimated yields (Kumhálová \& Matějková, 2017). This information is important and serves as a basis for future crop and yield monitoring especially in data-scarce areas.

The unavailability of satellite data throughout the year on all the areas entails that other missions should be employed. The use of different satellite data to a small extent evokes the challenges of discrepancy in the spatial and temporal variability in the observed areas. For instance, the coverage for most of Sentinel 2 is low in the lower latitudes. The high swath of the satellite sensors compounds this challenge. However, this is a tradeoff from the manufacturer's perspective. Limitations of the empirical approaches, which have been the basis for the simple crop yield estimation, decelerate the process of institutionalizing robust regional estimation. Consequently, new areas cannot easily be explored because extrapolation of such approaches is difficult. Efforts of minimizing these constraints, using crop models such as the ones based on the light-use and radiation-use efficiencies has provided some fresh light for further prospects (Lobell, 2013; Monteith \& Moss, 1977; Monteith, 1978). However, as far as crop yield forecasting at regional and local level is concerned, there is room to improve through the enhancement of data collection. There is still need to refine the spectral signatures for annual crops like cereals and pastures to improve yield predictions. Simultaneously, crop masks must be more updated and accurate to mask out the unwanted areas while preserving the area of interest. Similarly, incorporation of satellite-based biophysical parameters together with weather and climatic factors would better explain yield differences from a meteorological perspective.

Factoring in other yield-reducing factors such as wild fires, pests and diseases would also help improve forecasts and crop damage assessment by insurers. While some studies have isolated the spectral differences due to pest damage, more work on other crops remains (Abdel-Rahman et al., 2017). This will establish further relationships making crop yield estimations more objective in relation to underlying factors. Following this, Tonnang et al's (2017) recently well-tabulated holistic system of crop modeling will especially improve yield estimation in several aspects.

Inception works on NDVI have remained a strong basis for monitoring crop condition. NDVI is said to have an almost linear relationship between the fraction of photosynthetically active radiation and LAI. However, Vancutsem et al. (2013) reported that MODIS NDVI time-series data synthesis posed challenges when harmonizing which were overcome by employing more accurate crop masks. NDVI's saturating properties in dense canopies, or high biomass content has been reported and researchers are opting for combining it with indices that do not exhibit this characteristic, or altogether using other Vis such as EVI.

\subsection{Machine Learning and Crop Models}

As for machine learning, with on-going advances in computer technology, opportunities for further exploration of satellite data exist and require intricate investigation. Remarkably, the incorporation of ancillary data such as the local cropping calendar, calibrated and validated crop models for crop of interest will enrich the satellite-based inferences. Furthermore, there is need to harmonize both irrigated and rain-fed production, in estimation of phenological stages for the main energy crops. Clearly, remote sensing still has a greater role to play in agronomic, socio-economic and health of billions of people expected to survive under the scarcity of resources. As such, now is the best time to step up and refine the loopholes in promising methods. One place to start, following the availability of high-resolution data, is from previous models that performed well with coarse resolution data.

Like Morell et al.'s (2016), questions about predictions of crop yield along an entire growing belt still arise. Unless and until, efforts to scale up every option that has shown potential, such questions will linger in our minds and those of generations to come. Relying on agro-meteorological and statistical methods on crop yield forecasting alone should not be the main method of crop yield estimation. However, largely, a further expansion 
through local interactions by smart phone information provision by farmers to monitor cropping systems should be encouraged. Free pplications that capture crop type, planting dates, management practices, and phenological parameters can be installed in the smart phones for this purpose. This will help bridge the gap between some factors that influence yield estimation discrepancies, such intercropping, sowing dates, varieties, and weed or disease infestation. Additionally, it will also help whether to predict for an entire season or not, and for which crops (Li et al., 2015; Usaeed et al., 2017). Such aspects need to be agreed upon by experts.

Di Paola et al., (2016) argued that models do not explicitly include the accuracies as pertains to structure and functionality, and do not include alternative parametizations. Additionally, Incorporation of climatic projections in models increases precision in planning for extreme events according to different climatic forcing. Greenhouse gas concentration and temperature rise affect crop production as they affect photosynthesis and respiration processes. Therefore, employing multi-model configurations or multi-model ensembles is one of the major missing gaps needing consideration by crop modeling research.

Furthermore, researchers' steady provision of spatially reliable and consistent yield estimations will improve service delivery and strengthen decision-making among policy makers. Going an extra mile to understand other available satellite products, drivers of spatial variability in crop responses will result in more holistic results. Synergistic multi-disciplinary efforts equally need to be upheld both at regional and local levels to develop consistent methods of yield estimation. Simple models based on satellite data that stakeholders can use for planning purposes are required for maize crop in Southern Africa. Further research on crop yield estimation using high resolution satellite imagery among small holder farmers will improve decision making, and service delivery.

\section{Acknowledgements}

The author acknowledges support from the Chinese Academy of Sciences (CAS) and The World Academy of Sciences (TWAS) through the CAS-TWAS President's fellowship and The Seed Grant from the Directorate of Research and Graduate Studies (DRGS, The University of Zambia) to carry out the research.

\section{References}

Abdel-Rahman, E. M., Landmann, T., Kyalo, R., Ong'amo, G., Mwalusepo, S., \& Sulieman, S. (2017). Predicting stem borer density in maize using RapidEye data and generalized linear models. International Journal of Applied Earth Observation and Geoinformation, 57, 61-74. https://doi.org/10.1016/j.jag.2016. 12.008

Ali, I., Cawkwell, F., Dwyer, E., \& Green, S. (2017). Modeling managed grassland biomass estimation by using multitemporal remote sensing data-A machine learning approach. IEEE Journal of Selected Topics in Applied Earth Observations and Remote Sensing, 10, 3254-3264. https://doi.org/10.1109/JSTARS.2016. 2561618

Allen, M., Barros, V., Broome, J., Cramer, W., Christ, R., \& Church, J. (2014). Intergovernmental Panel on Climate Change Fifth Assessment Synthesis Report-Climate Change 2014 Synthesis Report. IPCC, Geneva, Switzerland.

Atzberger, C. (2013). Advances in remote sensing of agriculture: Context description, existing operational monitoring systems and information needs. Remote Sensing, 5, 949-981. https://doi.org/10.3390/rs5020949

Ban, H.-Y., Kim, K. S., Park, N.-W., \& Lee, B.-W. (2016). Using MODIS Data to Predict Regional Corn Yields. Remote Sensing, 9, 16. https://doi.org/10.3390/rs9010016

Battude, M., Al Bitar, A., Morin, D., Cros, J., Huc, M., Marais Sicre, C., ... Demarez, V. (2016). Estimating maize biomass and yield over large areas using high spatial and temporal resolution Sentinel-2 like remote sensing data. Remote Sensing of Environment, 184, 668-681. https://doi.org/10.1016/j.re.2016.07.030

Bellora, C., Blanc, É., Bourgeon, J.-M., \& Strobl, E. (2017). Estimating the impact of crop diversity on agricultural productivity in South Africa. National Bureau of Economic Research. https://doi.org/ $10.3386 / \mathrm{w} 23496$

Biffis, E., \& Chavez, E. (2017). Satellite data and machine learning for weather risk management and food security. Risk Analysis, 37, 1508-1521. https://doi.org/10.1111/risa.12847

Burke, M., \& Lobell, D. B. (2017). Satellite-based assessment of yield variation and its determinants in smallholder African systems. Proceedings of the National Academy of Sciences, 9, 2189-2194. 
Campos-Taberner, M., García-Haro, F. J., Camps-Valls, G., Grau-Muedra, G., Nutini, F., Busetto, L., ... Boschetti, M. (2017). Exploitation of SAR and optical sentinel data to detect rice crop and estimate seasonal dynamics of leaf area index. Remote Sensing, 9, 248. https://doi.org/10.3390/rs9030248

Chapoto, A., Chabala, L. M., \& Lungu, O. N. (2016). A Long History of Low Productivity in Zambia: Is it Time to Do Away with Blanket Recommendations? Zambia Social Science Journal, 6(2), Article 6. Retrieved from https://scholarship.law.cornell.edu/zssj/vol6/iss $2 / 6$

Chisanga, C. B., Phiri, E., Shepande, C., \& Sichingabula, H. (2015). Evaluating CERES-Maize model using planting dates and nitrogen fertilizer in Zambia. Journal of Agricultural Science, 7(3), 79. https://doi.org/ 10.5539/jas.v7n3p79

Clevers, J., Kooistra, L., \& van den Brande, M. (2017). Using Sentinel-2 Data for retrieving LAI and leaf and canopy chlorophyll content of a potato crop. Remote Sensing, 9, 405. https://doi.org/10.3390/rs9050405

Delincé, J. (2017). Recent practices and advances for AMIS crop yield forecasting at farm/parcel level: A review. FAO-AMIS Publication: Rome.

Delince, J. (2017). Use of remote sensing and drones in producing agricultural information. 2017 AAAS Annual Meeting, February 16-20, 2017.

Dempewolf, J., Adusei, B., Becker-Reshef, I., Hansen, M., Potapov, P., \& Khan, A. (2014). Wheat yield forecasting for punjab province from vegetation index time series and historic crop statistics. Remote Sensing, 6, 9653-9675. https://doi.org/10.3390/rs6109653

Di Paola A., Valentini, R., \& Santini, M. (2016). An overview of available crop growth and yield models for studies and assessments in agriculture. Journal of the Science of Food and Agriculture, 96, 709-714. https://doi.org/10.1002/jsfa.7359

Dong, T., Dong, T., Liu, J., Qian, B., Zhao, T., Jing, Q., ... Shang, J. (2016). Estimating winter wheat biomass by assimilating assimilating leaf area index derived from fusion of Landsat- 8 and MODIS data. International Journal of Applied Earth Observation and Geoinformation, 49, 63-74. https://doi.org/10.1016/j.jag. 2016.02.001

Erickson, J. (1984). The LACIE experiment in satellite aided monitoring of global crop production, the role of terrestrial vegetation in the global carbon cycle: Measurement by remote sensing (Vol. 23, pp. 191-217). John Wiley \& Sons Ltd.

Ferencz, C., Bognár, P., Lichtenberger, J., Hamar, D., Tarcsai, G., Timár, G., ... Ferencz-Árkos, I. (2004). Crop yield estimation by satellite remote sensing. International Journal of Remote Sensing, 25, 4113-4149. https://doi.org/10.1080/01431160410001698870

Fieuzal, R., \& Baup, F. (2017). Forecast of wheat yield throughout the agricultural season using optical and radar satellite images. International Journal of Applied Earth Observation and Geoinformation, 59, 147-156. https://doi.org/10.1016/j.jag.2017.03.011

Fieuzal, R., Sicre, C. M., \& Baup, F. (2016). Estimation of corn yield using multi-temporal optical and radar satellite data and artificial neural networks. International Journal of Applied Earth Observation and Geoinformation, 57, 14-23. https://doi.org/10.1016/j.jag.2016.12.011

Godfray, H. C. J., Beddington, J. R., Crute, I. R., Haddad, L., Lawrence, D., Muir, J. F., ... Toulmin, C. (2010). Food security: The challenge of feeding 9 billion people. Science, 327, 812-818, https://doi.org/10.1126/ science. 1185383

Gorelick, N., Hancher, M., Dixon, M., Ilyushchenko, S., Thau, D., \& Moore, R. (2017). Google Earth Engine: Planetary-scale geospatial analysis for everyone. Remote Sensing of the Environment, 202, 18-27. https://doi.org/10.1016/j.rse.2017.06.031

Guerschman, J. P., McKenzie, N. J., Held, A., \& Zurita-Milla, R. (2016). Advances in remote sensing for agricultural development and poverty alleviation. In N. J. McKenzie, A. D. Sparrow, \& J. P. Guerschman (Eds.), The role of remote sensing in agricultural development and poverty alleviation-The STARS Landscaping Study. CSIRO Australia Publication (Section 3): Canberra.

Hall, C., Dawson, T., Macdiarmid, J., Matthews, R., \& Smith, P. (2017). The impact of population growth and climate change on food security in Africa: looking ahead to 2050. International Journal of Agricultural Sustainability, 15, 124-135. https://doi.org/10.1080/14735903.2017.1293929 
Hunt, Jr. E. R., McMurtrey, P. C., Daughtry, J. E., Perry, E. M., \& Akhmedo, B. (2013). A visible band index for remote sensing leaf chlorophyll content at the canopy scale. International Journal of Applied Earth Observation and Geoinformation, 21, 103-112. https://doi.org/10.1016/j.jag.2012.07.020

Immitzer, M., Vuolo, F., \& Atzberger, C. (2016). First experience with Sentinel-2 data for crop and tree species classifications in central Europe. Remote Sensing, 8, 166. https://doi.org/10.3390/rs8030166

Jain, M., Singh, B., Srivastava, A., Malik, R. K., McDonald, A., \& Lobell, D. B. (2017). Using satellite data to identify the causes of and potential solutions for yield gaps in India's Wheat Belt. Environmental Research Letters, 12(9), 094011. https://doi.org/10.1088/1748-9326/aa8228

Jones, J. W., Antle, J. M., Basso, B., Boote, K. J., \& Conant, R. T. (2016). Brief history of agricultural systems Modeling. Agricultural Systems, in press. https://doi.org/10.1016/j.agsy.2016.05.014

Kim, J., \& Hogue, T. S. (2012). Evaluation and sensitivity testing of a coupled Landsat-MODIS downscaling method for land surface temperature and vegetation indices in semi-arid regions. Journal of Applied Remote Sensing, 6, 063569-1. https://doi.org/10.1117/1.JRS.6.063569

Knox, J., Hess, T., Daccache, A., \& Wheeler, T. (2012). Climate change impacts on crop productivity in Africa and South Asia. Environmental Research Letters, 7, 034032. https://doi.org/10.1088/1748-9326/7/3/034032

Kumhálová, J., \& Matějková, Š. (2017). Yield variability prediction by remote sensing sensors with different spatial resolution. International Agrophysics, 31, 195-202. https://doi.org/10.1515/intag-2016-0046

Kuri, F., Murwira, A., Murwira, K. S., \& Masocha, M. (2017). Accounting for phenology in maize yield prediction prediction using remotely sensed dry dekads. Geocarto International, 1-14. https://doi.org/ 10.1080/10106049.2017.1299798

Kuwata, K., \& Shibasaki, R. (2016). Estimating corn yield in the united states with MODIS evi and machine learning methods. ISPRS Annals of Photogrammetry, Remote Sensing \& Spatial Information Sciences, 3. https://doi.org/10.5194/isprsannals-III-8-131-2016

Leff, B., Ramankutty, N., \& Foley, J. A. (2004). Geographic distribution of major crops across the world. Global Biogeochemical Cycles, 18. https://doi.org/10.1029/2003GB002108

Li, H., Chen, Z., Liu, G., Jiang, Z., \& Huang, C. (2017). Improving Winter Wheat Yield Estimation from the CERES-Wheat Model to Assimilate Leaf Area Index with Different Assimilation Methods and Spatio-Temporal Scales. Remote Sensing, 9, 190. https://doi.org/10.1016/j.agrformet.2015.02.0010168-1923

Li, W., Niu, Z., Wang, C., Huang, W., Chen, H., Gao, S., ... Muhammad, S. (2015). Combined use of airborne LiDAR and satellite GF-1 data to estimate leaf area index, height, and aboveground biomass of maize during peak growing season. IEEE Journal of Selected Topics in Applied Earth Observations and Remote Sensing, 8, 4489-4501. https://doi.org/10.1109/JSTARS.2015.2496358

Liaqat, M. U., Cheema, M. J. M., Huang, W., Mahmood, T., Zaman, M., \& Khan, M. M. (2017). Evaluation of MODIS and Landsat multiband vegetation indices used for wheat yield estimation in irrigated Indus Basin. Computers and Electronics in Agriculture, 138, 39-47. https://doi.org/10.1016/j.compag.2017.04.006

Liu, J., Pattey, E., Miller, J. R., McNairn, H., Smith, A., \& Hu, B. (2010). Estimating crop stresses, aboveground dry biomass and yield of corn using multi-temporal optical data combined with a radiation use efficiency model. Remote Sensing of Environment, 114, 1167-1177. https://doi.org/10.1016/j.rse.2010.01.004

Lobell, D. B. (2013). The use of satellite data for crop yield gap analysis. Field Crops Research, 143, 56-64. https://doi.org/10.1016/j.fcr.2012.08.008

Ma, G., Huang, J., Wu, W., Fan, J., Zou, J., \& Wu, S. (2013). Assimilation of MODIS-LAI into the WOFOST model for forecasting regional winter wheat yield. Mathematical and Computer Modelling, 58, 634-643. https://doi.org/10.1016/j.mcm.2011.10.038

Monteith, J. (1972). Solar radiation and productivity in tropical ecosystems. Journal of Applied Ecology, 9, 747-766. https://doi.org/10.2307/2401901

Monteith, J. L., \& Moss, C. (1977). Climate and the efficiency of crop production in Britain. Philosophical Transactions of the Royal Society of London B: Biological Sciences, 281, 277-294. https://oi.org/10.1098/ rstb.1977.0140 
Morell, F. J., Yang, H. S., Cassman, K. G., Van Wart, J., Elmore, R. W., Licht, M., ... Grassini, P. (2016). Can crop simulation models be used to predict local to regional maize yields and total production in the US Corn Belt? Field Crops Research, 192, 1-12. https://doi.org/10.1016/j.fcr.2016.04.004

Msowoya, K., Madani, K., Davtalab, R., Mirchi, A., \& Lund, J. R. (2016). Climate change impacts on maize production in the warm heart of Africa. Water Resources Management, 30, 5299-5312. https://doi.org/ $10.1007 / \mathrm{s} 11269-016-1487-3$

Mulla, D. J. (2013). Twenty-five years of remote sensing in precision agriculture: Key advances and remaining knowledge gaps. Biosystems Engineering, 114, 358-371. https://doi.org/10.1016/j.biosystemseng.2012. 08.009

Ntukamazina, N., Onwonga, R. N., Sommer, R., Rubyogo, J.-C., Mukankusi, C. M., Mburu, J., \& Kariuki, R. (2017). Index- based agricultural insurance products: Challenges, opportunities and prospects for uptake in sub-Sahara Africa. Journal of Agriculture and Rural Development in the Tropics and Subtropics, 118, 171-185. Retrieved from http://nbn-resolving.de/urn:nbn:de:hebis:34-2017042052372

Rembold, F., Atzberger, C., Savin, I., \& Rojas, O. (2013). Using low resolution satellite imagery for yield prediction and yield anomaly detection. Remote Sensing, 5, 1704-1733. https://doi.org/10.3390/rs5041704

Ross, K., Brown, M. E., Verdin, J., \& Underwood, L. (2009). Review of FEWS NET biophysical monitoring Requirements. Environmental Research Letters, 4, 024009. https://doi.org/10.1088/1748-9326/4/2/024009

Saeed, U., Dempewolf, J., Becker-Reshef, I., Khan, A., Ahmad, A., \& Wajid, S. A. (2017). Forecasting wheat yield from weather data and MODIS NDVI using Random Forests for Punjab province, Pakistan. International Journal of Remote Sensing, 38, 4831-4854. https://doi.org/10.1080/01431161.2017.1323282

Senay, G., Velpuri, N. M., Bohms, S., Budde, M., Young, C., Rowland, J., \& Verdin J. P. (2015). Drought monitoring and assessment: Remote sensing and modeling approaches for the Famine Early Warning Systems Network. Hydro-Meteorological Hazards, Risks, and Disasters, 233-262. https://doi.org/10.1016/ B978-0-12-394846-5.00009-6

Shepande, C. (2010). Development of geo-spatial analysis tools for inventory and mapping of soils of the Chongwe Region of Zambia (Doctoral dissertation, University of Minnesota, St. Paul, USA).

Shoko, C., \& Mutanga, O. (2017). Seasonal discrimination of C3 and C4 grasses functional types: An evaluation evaluation of the prospects of varying spectral configurations of new generation sensors. International Journal of Applied Earth Observation and Geoinformation, 62, 47-55. https://doi.org/10.1016/j.jag. 2017.05.015

Silvestro, P., Pignatti, S., Pascucci, S., Yang, H., Li, Z., Yang, G., ... Casa, R. (2017). Estimating Wheat Yield in China at the Field and District Scale from the Assimilation of Satellite Data into the Aquacrop and Simple Algorithm for Yield (SAFY) Models. Remote Sensing, 9, 509. https://doi.org/10.3390/rs9050509

Spitkó, T., Nagy, Z., Zsubori, Z. T., Szőke, C., Berzy, T., Pintér, J., \& Marton, C. L. (2016). Connection between normalized difference vegetation index and yield in maize. Plant, Soil and Environment, 62, 293-298. https://doi.org/10.17221/676/2015-PSE

Srivastava, A. K., Mboh, C. M., Gaiser, T., Webber, H., \& Ewert, F. (2016). Effect of sowing date distributions on on simulation of maize yields at regional scale-A case study in Central Ghana, West Africa. Agricultural Systems, 147, 10-23. https://doi.org/10.1016/j.agsy.2016.05.012

Srivastava, A. K., Mboh, C. M., Zhao, G., Gaiser, T., \& Ewert, F. (2017). Climate change impact under alternate realizations of climate scenarios on maize yield and biomass in Ghana. Agricultural Systems, 159, 157-174. https://doi.org/10.1016/j.agsy.2017.03.011

Steele-Dunne, S. C., McNairn, H., Monsivais-Huertero, A., Judge, J., Liu, P. W., \& Papathanassiou, K. (2017). Radar remote sensing of agricultural canopies: A review. IEEE Journal of Selected Topics in Applied Earth Observations and Remote Sensing, 5, 2249-73. https://doi.org/10.1109/JSTARS.2016.2639043

Stefano Bocchi, M. B. (2011). Estimation of rice production at regional scale with a Light Use Efficiency model and MODIS time series. Italian Journal of Remote Sensing, 63-81. https://doi.org/10.5721/ItJRS20114335

Sun, L., Gao, F., Anderson, M. C., Kustas, W. P., Alsina, M. M., Sanchez, L., ... Post, K. (2017). Daily Mapping of 30m LAI and NDVI for Grape Yield Prediction in California Vineyards. Remote Sensing, 9, 317. https://doi.org/10.3390/rs9040317 
Tonnang, H. E., Herv, B. D., Biber-Freudenberger, L., Salifu, D., Subramanian, S., Ngowi, V. B., ... Borgemeister, C. (2017). Advances in crop insect modelling methods - Towards a whole system approach. Ecological Modelling, 354, 88-103. https://doi.org/10.1016/j.ecolmodel.2017.03.015

Unganai, L. S., \& Kogan, F. N. (1998). Drought monitoring and corn yield estimation in Southern Africa from AVHRR data. Remote Sensing of Environment, 63, 219-232. https://doi.org/10.1016/S0034-4257(97) 00132-6

United Nations. (2015). Sustainable Development Goals. UN, Rome, Italy.

Van Ittersum, M. K., Cassman, K. G., Grassini, P., Wolf, J., Tittonell, P., \& Hochman, Z. (2013). Yield gap analysis with local to global relevance-A review. Field Crops Research, 143, 4-17. https://doi.org/ 10.1016/j.fcr.2012.09.009

Van Ittersum, M. K., Van Bussel, L. G., Wolf, J., Grassini, P., Van Wart, J., \& Guilpart, N. (2016). Can sub-Saharan Saharan Africa feed itself? Proceedings of the National Academy of Sciences, 113, 14964-14969. https://doi.org/10.1073/pnas.1610359113

Van Oort, P. A., de Vries, M. E., Yoshida, H., \& Saito, K. (2015). Improved climate risk simulations for rice in arid Environments. PLoS One, 10. https://doi.org/10.1371/journal.pone.0118114

Vancutsem, C., Marinho, E., Kayitakire, F., See, L., \& Fritz, S. (2013). Harmonizing and Combining Existing Land Cover/Land Use Datasets for Cropland Area Monitoring at the African Continental Scale. Remote Sensing, 5, 19. https://doi.org/10.1371/journal.pone.0118114

Vergara-Díaz, O., Zaman-Allah, M. A., Masuka, B., Hornero, A., Zarco-Tejada, P., Prasanna, P. B. M., ... Araus José, L. (2016). A Novel Remote Sensing Approach for Prediction of Maize Yield Under Different Conditions of Nitrogen Fertilization. Frontiers in Plant Science, 7. https://doi.org/10.3389/fpls.2016.00666

Wei, X., Gu, X., Meng, Q., Yu, T., Zhou, X., Wei, Z., ... Wang, C. (2017). Leaf Area Index Estimation Using Chinese GF-1 GF-1 Wide Field View Data in an Agriculture Region. Sensors (Basel), 17. https://doi.org/ $10.3390 / \mathrm{s} 17071593$

Wheeler, T., \& Von Braun, J. (2013). Climate change impacts on global food security. Science, 341, 508-508-513. https://doi.org/10.1126/science.1239402

Wójtowicz, M., Wójtowicz, A., \& Piekarczyk, J. (2016). Application of remote sensing methods in agriculture. Communications in Biometry and Crop Science, 11, 31-50.

Wu, B., Gommes, R., Zhang, M., Zeng, H., Yan, N., Zou, W., ... Van Heijden, A. (2015). Global crop monitoring: A satellite based hierarchical approach. Remote Sensing, 7, 3907-3933. https://doi.org/10.3390/rs70403907

Wu, B., Shukri, A., \& He, C. (2017). Shared Agronomic Information Community for the Belt and Road Initiative. Bulletin of Chinese Academy of Sciences, 32, 34-41.

You, J., Li, X., Low, M., Lobell, D., \& Ermon, S. (2017). Deep Gaussian Process for Crop Yield Prediction Based on Remote Sensing Data (pp. 4559-4566). Association for the Advancement of Artificial Intelligence.

Zhang, B., Zhang, L., Xie, Yin, X., Liu, C., \& Liu, G. (2015). Application of Synthetic NDVI Time Series Blended from Landsat and MODIS Data for Grassland Biomass Estimation. Remote Sensing, 8, 10. https://doi.org/10.3390/rs8010010

Zhang, X., Xu M., Sun, N., Xiong, W., Huang, S., \& Wu, L. (2016). Modelling and predicting crop yield, soil carbon and nitrogen stocks under climate change scenarios with fertiliser management in the North China Plain. Geoderma, 265, 176-186. https://doi.org/10.1016/j.geoderma.2015.11.027

Zheng, Y., Zhang, M., Zhang, X., Zeng, H., \& Wu, B. (2016). Mapping winter wheat biomass and yield using time series data blended from PROBA-V 100-and 300-m S1 products. Remote Sensing, 8, 824. https://doi.org/10.3390/rs8100824 


\section{Appendix A}

\section{Table showing commonly used crop models in the last two decades.}

Table A1. Crop models summary (Modified from Delincé, 2017)

\begin{tabular}{|c|c|c|c|c|c|c|c|}
\hline Name & $\begin{array}{l}\text { Crop growth } \\
\text { model type }\end{array}$ & Sub-model & $\begin{array}{l}\text { Scale of } \\
\text { Application }\end{array}$ & Time step & Crop addressed & $\begin{array}{l}\text { Examples of } \\
\text { where applied }\end{array}$ & $\begin{array}{l}\text { Code/Software } \\
\text { availability }\end{array}$ \\
\hline AgroMetShell & Hybrid & W & $\begin{array}{l}\text { Regional } \\
\text { to Global } \\
\text { (Ecosystems ) }\end{array}$ & Decadal & maize, millet, tef, beans, wheat, sorghum & $\begin{array}{l}\text { Pakistan, Zambia, } \\
\text { French }\end{array}$ & $\begin{array}{l}\text { Executable } \\
\text { software for } \\
\text { Windows with } \\
\text { GUI (AO) }\end{array}$ \\
\hline APSIM & $\begin{array}{l}\text { Mechanistic } \\
\text { (from CERES } \\
\text { and ORYZA) }\end{array}$ & $\mathrm{W}, \mathrm{N}, \mathrm{C}$ & Field & Daily & $\begin{array}{l}\text { barley, canola, canopy(intercropping), } \\
\text { chickpea, cowpea, fababean, field pea, } \\
\text { horse gram, lablab, lupins, maize, millet, } \\
\text { mucuna, mungbean, oil palm, peanut, } \\
\text { pigeon pea, plant, rice, slurp, sorghum, } \\
\text { soybean, sugar, weed wheat, cotton }\end{array}$ & $\begin{array}{l}\text { Queensland, } \\
\text { Netherlands, } \\
\text { Zimbabwe, } \\
\text { Australia }\left(\mathrm{V}^{13}\right)\end{array}$ & $\begin{array}{l}\text { Fortran } \mathrm{C}++, \\
\text { Linux Shell (AO) }\end{array}$ \\
\hline AquaCrop & Empirical & W & Field & Daily & $\begin{array}{l}\text { cotton, maize, potato, quinoa, } \\
\text { rice, soybean, sugar beet, } \\
\text { sunflower, tomato and wheat }\end{array}$ & $\begin{array}{l}\text { Bushland, TX; } \\
\text { Gainesville, FL; and } \\
\text { Zaragoza, Spain }\left(\mathrm{V}^{17}\right)\end{array}$ & $\begin{array}{l}\text { Executable } \\
\text { software for } \\
\text { Windows with } \\
\text { GUI (AO) }\end{array}$ \\
\hline CropSyst & $\begin{array}{l}\text { Mechanistic } \\
\text { (from EPIC) }\end{array}$ & $\mathrm{W}, \mathrm{N}$ & Field & Daily & $\begin{array}{l}\text { corn, wheat, barley, soybean, } \\
\text { sorghum, and lupins }\end{array}$ & $\begin{array}{l}\text { USA, Southern France, } \\
\text { Italy, Syria, Spain, } \\
\text { Australia }\left(\mathrm{V}^{37}\right)\end{array}$ & $\begin{array}{l}\mathrm{C}++, \mathrm{GUI} \text { available } \\
\text { for windows }(\mathrm{AO})\end{array}$ \\
\hline DayCent & Mechanistic & $\mathrm{W}, \mathrm{N}, \mathrm{C}$ & $\begin{array}{l}\text { Regional } \\
\text { to Global } \\
\text { (Ecosystems ) }\end{array}$ & Daily & major crops & Global $\left(\mathrm{V}^{41}\right)$ & $\mathrm{C}++(\mathrm{AR})$ \\
\hline DSSAT & $\begin{array}{l}\text { includes CERES, } \\
\text { CROPGRO, } \\
\text { CROPSIM, } \\
\text { CABEGRO } \\
\text { and others }\end{array}$ & $\mathrm{W}, \mathrm{N}, \mathrm{C}$ & Field & Daily & $\begin{array}{l}\text { over } 28 \text { crops (Including: maize, wheat, } \\
\text { soybean, peanut, rice, potato, tomato, } \\
\text { drybean, sorghum, millet, pasture, } \\
\text { chickpea, cowpea, velvetbean, } \\
\text { brachiaria grass, and fababean) }\end{array}$ & $\begin{array}{l}\text { over } 100 \text { countries } \\
\text { worldwide (V43) }\end{array}$ & $\begin{array}{l}\text { Fortran Software } \\
\text { package (AO) }\end{array}$ \\
\hline FARMSIM* & Empirical & $\mathrm{W}, \mathrm{N}, \mathrm{C}, \mathrm{K}$ & Field & Monthly & $\begin{array}{l}\text { maize, common beans, cassava, bananas, } \\
\text { cotton, sorghum, bambara beans, sweet } \\
\text { potatoes, coffee, finger millet, ground } \\
\text { nuts, yams palms, pearl millet, cowpea, } \\
\text { taro tea, soybean, potatoes, pigeon pea }\end{array}$ & $\begin{array}{l}\text { sub-Saharan Africa; } \\
\text { Zimbabwe }\end{array}$ & $\begin{array}{l}\text { Microsoft }{ }^{\circledR} \text { Excel } \\
\text { using SimetarC (AO) }\end{array}$ \\
\hline GLAM & Hybrid & W & $\begin{array}{l}\text { Regional } \\
\text { to Global }\end{array}$ & Daily & groundnut, wheat and maize & $\begin{array}{l}\text { India, Africa, } \\
\text { China }\left(\mathrm{V}^{51}\right)\end{array}$ & $\begin{array}{l}\text { Executable } \\
\text { software (AR) }\end{array}$ \\
\hline InfoCrop & $\begin{array}{l}\text { Mechanistic } \\
\text { (from SUCROS } \\
\text { and ORYZA) }\end{array}$ & $\mathrm{W}, \mathrm{N}, \mathrm{C}$ & Field & Daily & $\begin{array}{l}\text { annual cereals, legumes, oilseeds, } \\
\text { potato and sugarcane }\end{array}$ & $\begin{array}{l}\text { India, Ludhiana, } \\
\text { Africa }\left(\mathrm{V}^{62}\right)\end{array}$ & $\begin{array}{l}\text { Fortran,, GUI for } \\
\text { windows (AO) }\end{array}$ \\
\hline JULES-crop & $\begin{array}{l}\text { Mechanistic } \\
\text { (from SUCROS) }\end{array}$ & $\mathrm{W}$ & $\begin{array}{l}\text { Regional } \\
\text { to Global } \\
\text { (Ecosystems ) }\end{array}$ & Daily & 12 CFTs & Global $\left(\mathrm{V}^{63}\right)$ & FORTRAN \\
\hline LPJmL & $\begin{array}{l}\text { Mechanistic } \\
\text { (from EPIC) }\end{array}$ & W & $\begin{array}{l}\text { Regional } \\
\text { to Global } \\
\text { (Ecosystems ) }\end{array}$ & Daily & 13 CFTs & Global $\left(\mathrm{V}^{67}\right)$ & $\mathrm{C}++(\mathrm{AO})$ \\
\hline PEGASUS & Hybrid & W & $\begin{array}{l}\text { Regional } \\
\text { to Global } \\
\text { (Ecosystems ) }\end{array}$ & Daily & maize, soybeans, spring wheat and others & Global $\left(\mathrm{V}^{78}\right)$ & \\
\hline WOFOST & $\begin{array}{l}\text { Hybrid } \\
\text { (from SUCROS) }\end{array}$ & W & Field/regional & Daily & $\begin{array}{l}\text { annual field crop: winter wheat, spring } \\
\text { barley, grain and green maize, potatoes, } \\
\text { sugar beet, rapeseed, beans, soybean } \\
\text { and rice }\end{array}$ & $\begin{array}{l}\text { Europe, Russia, Black } \\
\text { Sea and CIS countries, } \\
\text { China and India }\left(\mathrm{V}^{103}\right)\end{array}$ & $\begin{array}{l}\text { Fortran77, } \\
\text { with a GUI for } \\
\text { windows }(\mathrm{AO})\end{array}$ \\
\hline
\end{tabular}

\section{Copyrights}

Copyright for this article is retained by the author(s), with first publication rights granted to the journal.

This is an open-access article distributed under the terms and conditions of the Creative Commons Attribution license (http://creativecommons.org/licenses/by/4.0/). 